Article

\title{
Experimental and Numerical Studies on the Influence of Blade Number in a Small Water Turbine
}

\author{
Grzegorz Peczkis ${ }^{1, *}$, Piotr Wiśniewski ${ }^{1}$ (D) and Andriy Zahorulko ${ }^{2}$ (D) \\ 1 Department of Power Engineering and Turbomachinery, The Silesian University of Technology, \\ 44-100 Gliwice, Poland; piotr.wisniewski@polsl.pl \\ 2 Volodymyr Martsynkovskyy Computational Mechanics Department, Sumy State University, \\ 40007 Sumy, Ukraine; a.zagorulko@omdm.sumdu.edu.ua \\ * Correspondence: grzegorz.peczkis@polsl.pl
}

Citation: Peczkis, G.; Wiśniewski, P.; Zahorulko, A. Experimental and Numerical Studies on the Influence of Blade Number in a Small Water Turbine. Energies 2021, 14, 2604 https://doi.org/10.3390/en14092604

Academic Editor: Davide Astolfi

Received: 23 March 2021

Accepted: 26 April 2021

Published: 2 May 2021

Publisher's Note: MDPI stays neutral with regard to jurisdictional claims in published maps and institutional affiliations.

Copyright: (c) 2021 by the authors. Licensee MDPI, Basel, Switzerland. This article is an open access article distributed under the terms and conditions of the Creative Commons Attribution (CC BY) license (https:// creativecommons.org/licenses/by/ $4.0 /)$.

\begin{abstract}
This paper demonstrates the procedure of blade adjustment in a Kaplan-type water turbine, based on calculations of the flow system. The geometrical adjustment of a twisted blade with varying chord length is described in the study. Computational fluid dynamics (CFD) analysis was used to characterise aerofoil and turbine performance. Furthermore, two turbines, with a different number of blades, were designed, manufactured, and tested experimentally. The numerical model results were then compared with the experimental data. The studies were carried out with different rotational velocities and different stator blade incidence angles. The paper shows a comparison of the turbine efficiencies that were assessed, using numerical and experimental methods, of a flow system with four- and five-bladed rotors. The numerical model results matched up well with those of the experimental study. The efficiency of the proposed turbines reached up to $72 \%$ and $84 \%$ for fourbladed and five-bladed designs, respectively. These efficiencies, when considered with the turbine's simplicity, low production and maintenance costs, as well as their potential for harvesting energy from low energy flows, mean that Kaplan turbines provide a promising technology for processing renewable energy.
\end{abstract}

Keywords: small water turbines; renewable energy; Kaplan turbine; CFD

\section{Introduction}

In recent times, there has been a strong interest in replacing conventional power plants, powered by fossil fuels, with renewable energy sources [1]. Individually, many European countries have pushed development in their energy sectors towards nuclear, wind, and solar power. The introduction of biomass and weather-fuelled power generation to the energy grid has increased expectations of emission-free energy systems. Hydropower technologies can help to fulfil these expectations. In well-developed countries, hydropower technologies are already commonly used to harvest power from high-energy water sources; however, lower-energy water sources are mostly not [2]. Consequently, small water turbines are experiencing a renaissance [3-5].

The need for harvesting energy from relatively small water flows, which has been disregarded for years, creates challenges for engineers to design systems since readymade algorithms are not available in the literature. New water turbine systems have to be designed since the operating conditions are very different than those used for large water flows. Many innovative, small turbines are now being developed to fill the previous void; one example of these is jet turbines. New prototypes are also being developed that combine new design concepts with tried and tested classical designs. Due to the ongoing improvement of numerical tools, it has become much easier to improve the efficiency of turbine designs. However, this has resulted in the temptation to continuously make small improvements, which, for relatively simple and cheap constructions, is not economically justified [6]. 
Results from Zhao et al. [7] have shown that small turbines present lots of potential for generating high-efficiency hydropower, whilst also showing increased flexibility over larger turbines during times of lower power demand.

Due to legislation that affects conventional power plants, the rise of environmental awareness, and the increase of fossil fuel cost, the price of energy continues to rise steadily. The dependence of energy cost on current weather conditions has become increasingly noticeable. Due to the restrictions in production and exceptionally favourable atmospheric conditions, Germany exceeded 55\% of power production from renewable energy sources in 2020 [8]. However, in addition to a positive change for the environment, this is also a large challenge for the energy grid, which has to deal with lower demand for power. Small water turbines are a promising solution to increasing the flexibility of the power system so that it can deal with periods of lower demand. This is because small turbine units work with small water flows and can therefore be turned on at any time to meet the power demand caused by the change of energy production, which may be caused by weather-condition-dependent units. As in the case of other renewable energy sources, their effectiveness is going to depend on the scale of water stream utilisation. This reasoning prompted the authors to investigate small water turbine design, specifically to present the procedure of blade formation of water turbines for small power units.

The Kaplan-type water turbine presented in this paper is shown to harvest energy successfully in a way that does not emit harmful substances into the atmosphere. The development of small water turbines is important because of the future possibility of storing energy in pumped storage power plants using water, also in closed circuits. According to the authors, this is a real, structurally and operationally proven alternative to temporary power generation from fossil fuel sources. The presented turbine can generate electricity from the water flow within five minutes of activation and can be operated virtually. The presented, structurally novel $2 \mathrm{~kW}$ turbine is an example of the application of the computational algorithm quoted in this paper and the authors' observations and described methods.

\section{Blade}

In the blade design process of the rotor, used in axial water turbines, aerofoils are usually selected from a database [9]. The sub-profiles are preselected based on the rotor application, for example, based on the working fluid, i.e., air or water, and the working parameters, i.e., Reynolds number. The sub-profiles are customarily catalogued based on the nomenclature adopted by research centres from all over the world [10], an example of which are the aerofoils that have been accepted by the National Advisory Committee for Aeronautics (NACA), which are described with several digits that distinctly specify the sub-profile geometry. The description of the characteristic elements of the sub-profile is shown in Figure 1. The research centres, which have manufactured and studied water turbines and pumps, recommend using the four-digit NACA sub-profiles. The adjustments of sub-profiles, based on the four- and five-digit NACA sub-profiles, are shown in this work. The modified sub-profiles are the results of analytical curves.

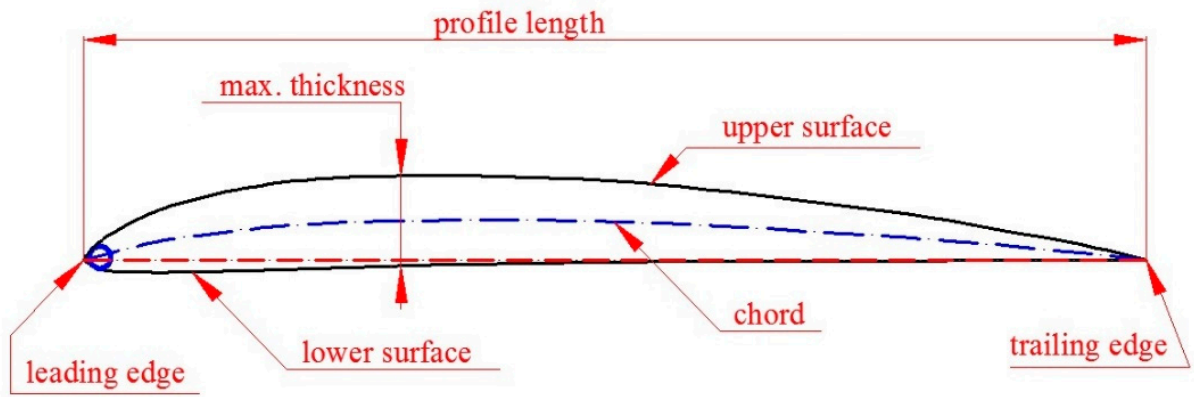

Figure 1. Characteristic elements of the sub-profile. 
The aerofoil performance is customarily described with lift and drag coefficient curves, as a function of the angle of attack. The lift and drag coefficients are non-dimensional values that relate the lift and drag forces to the blade size and flow conditions around it. These coefficients are described as follows:

$$
\begin{gathered}
C_{l}=\frac{L}{\frac{1}{2} \rho u^{2} c} \\
C_{d}=\frac{D}{\frac{1}{2} \rho u^{2} c}
\end{gathered}
$$

where $L$ is the lift force, $D$ is the drag force, $\rho$ is the fluid density, $u$ is the fluid velocity, and $c$ is the chord length, which, for 2D applications, has a dimension of $\mathrm{m}^{2}$. It must be pointed out that the available databases of aerofoil characteristics are based on airflow, and due to the large difference in fluid viscosity, they usually cannot be used for waterbased applications. However, the characteristics can be recomputed while maintaining a similarity number, named the Reynolds number, that is given by the following equation:

$$
\operatorname{Re}=\frac{u \cdot c}{v}
$$

where $u$ is the free stream velocity, $c$ denotes the chord length, and $v$ is the kinetic viscosity (equal to $1.46 \cdot 10^{-5} \frac{\mathrm{m}^{2}}{\mathrm{~s}}$ for air and to $1.07 \cdot 10^{-6} \frac{\mathrm{m}^{2}}{\mathrm{~s}}$ for water, if the temperature is equal to $20{ }^{\circ} \mathrm{C}$ ). Due to the difference in viscosity, flow character changes, which means that the Reynolds number differs by an order of magnitude depending on whether the fluid used is air or water. Therefore, it is important to acknowledge this limitation in the aerofoils database.

The procedure of geometry change is shown, in which the length and thickness proportionality is not preserved. The geometrical adjustment is required to achieve the desired values of the chord length $L$ and the thickness $s$. These optimal values are obtained from the flow system calculations. As a result, a modified sub-profile for a specific machine is created.

In the case of water turbines, one blade combines different aerofoils, whose weight centre is split radially. Subsequent aerofoils have different leaning angles $\beta$. Blade length is calculated from the empirical relations available in the literature [11-15]. The blade thickness is limited by material strength and the blade hub connection.

Blade geometry is transformed through subsequent aerofoils (see Figure 2), and the number of sub-profiles defines its twist and deformation rate. The number of subprofiles must be chosen carefully to avoid blade face warping due to the imperfection of manufacturing processes [16,17].

In the design of water turbine blades, the first step is to obtain an optimal solution in regard to the water flow, followed by designing the blade hub connection [18]. The connection is defined by the constructional solution and the incidence angle regulation system. The size and construction of the mounting are determined by the material strength to withstand the forces exerted by the fluid. The mechanism of blade incidence angle change must give the possibility of the clearance cassation to prevent blade vibrations. 


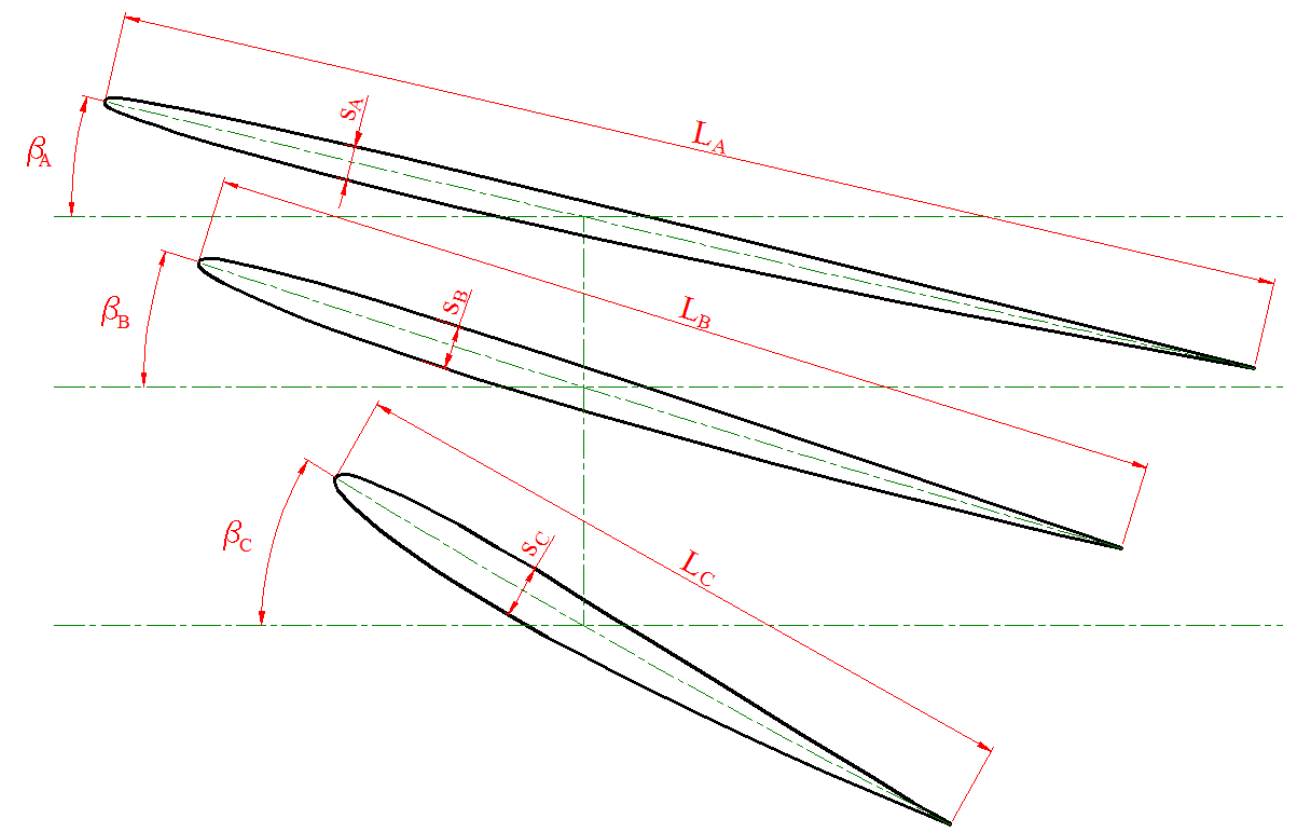

Figure 2. Aerofoil geometry in three subsequent cross sections. Plane view.

\section{Sub-Profile Geometry Adjustment}

The original aerofoil proposed for the water flow is shown in Figure 3. Its maximum thickness occurs $30 \%$ of the way along the chord length and is $8.25 \%$ of the chord length value. For further studies, the closed sub-profile has been changed into two splines, which create the upper and the lower part of the aerofoil. In Figure 3, points P00 and P16, namely, the leading and trailing points, are common for both curves.

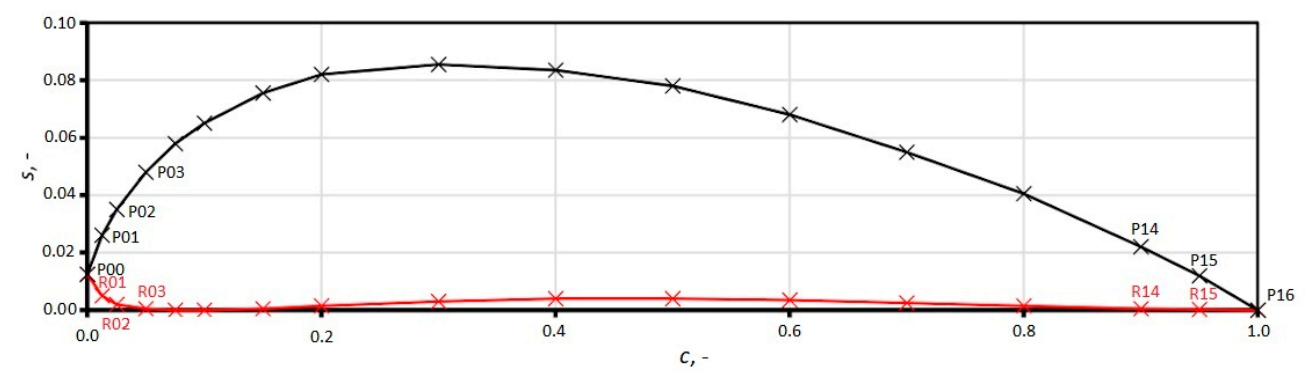

Figure 3. Aerodynamic sub-profile divided into upper and lower splain and the coordinates of its characteristic points.

The numerical analysis of the flow defines the blade chord length in subsequent sections. Based on the assumptions for flow calculation and the material strength, we obtain the blade thickness in the following subsections. Additionally, the vibration of excessively thin blades and water pollution (sand, mud, etc.) have to be taken into consideration. For clarity, the assumed sub-profile details have been provided in Table 1 and the coordinates of points along the aerofoil curves are shown in Table 2.

Table 1. Details of blade sub-profiles.

\begin{tabular}{cccc}
\hline Position & Sub-Profile & Length, $\mathbf{m m}$ & Thickness, $\mathbf{m m}$ \\
\hline Blade root & A & 103.74 & 8 \\
Blade at 50\% height & B & 145.60 & 6 \\
Blade tip & C & 178.44 & 4 \\
\hline
\end{tabular}


Table 2. Coordinates of characteristic points along with the blade upper and lower curve for the sub-profile of thickness $s_{A}=8 \mathrm{~mm}$ and length $L_{A}=103.74$.

\begin{tabular}{ccccc}
\hline Point Number & Chord Length & Upper Surface & Lower Surface & Thickness \\
\hline $\boldsymbol{n}$ & $\boldsymbol{L}_{\boldsymbol{A}}, \mathbf{m m}$ & $\boldsymbol{P}_{\boldsymbol{A} \boldsymbol{Y} \boldsymbol{}, \mathbf{m m}}$ & $\boldsymbol{P}_{\boldsymbol{A} \boldsymbol{X}}, \mathbf{m m}$ & $\mathbf{s}, \mathbf{m m}$ \\
\hline 00 & 0.000 & 1.212 & 1.212 & 0.000 \\
01 & 1.297 & 2.521 & 0.485 & 2.036 \\
02 & 2.594 & 3.394 & 0.194 & 3.200 \\
03 & 5.187 & 4.655 & 0.048 & 4.606 \\
04 & 7.781 & 5.624 & 0.000 & 5.624 \\
05 & 10.374 & 6.303 & 0.000 & 6.303 \\
06 & 15.561 & 7.321 & 0.048 & 7.273 \\
07 & 20.749 & 7.952 & 0.145 & 7.806 \\
08 & 31.123 & 8.291 & 0.291 & 8.000 \\
09 & 41.497 & 8.097 & 0.388 & 7.709 \\
10 & 51.872 & 7.564 & 0.388 & 7.176 \\
11 & 62.246 & 6.594 & 0.339 & 6.255 \\
12 & 72.620 & 5.333 & 0.242 & 5.091 \\
13 & 82.994 & 3.927 & 0.145 & 3.782 \\
14 & 93.369 & 2.133 & 0.048 & 2.085 \\
15 & 98.556 & 1.164 & 0.019 & 1.144 \\
16 & 103.743 & 0.000 & 0.000 & 0.000 \\
\hline
\end{tabular}

These values are the results of computations based on the Varchola algorithm [12]. If the blade size restrictions are known, the midspan sub-profile can be specified. Based on the maximum blade thickness of the original sub-profile and the desired thickness of the adjusted sub-profile, the ratio of thickness change, $k_{s}$, is specified for each sub-profile as follows:

$$
\begin{aligned}
& k_{s A}=\frac{s_{N}}{s_{A}}=\frac{8.25}{8}=1.031 \\
& k_{s B}=\frac{s_{N}}{s_{B}}=\frac{8.25}{6}=1.375 \\
& k_{s C}=\frac{s_{N}}{s_{C}}=\frac{8.25}{4}=2.0625
\end{aligned}
$$

where $s_{N}$ is the initial sub-profile thickness. The upper and lower coordinates in $\mathrm{Y}$ directions are scaled using the set of proportionality ratios for each sub-profile, as follows:

$$
\begin{aligned}
& P_{A Y}=P * k_{S A} \\
& P_{B Y}=P * k_{S B} \\
& P_{C Y}=P * k_{S C}
\end{aligned}
$$

The identical procedure is applied to designate the chord length ratio, $k_{L}$. The ratios are designated as follows:

$$
\begin{aligned}
& k_{L A}=\frac{L_{A}}{L_{N}}=\frac{103.74}{100}=1.0374 \\
& k_{L B}=\frac{L_{B}}{L_{N}}=\frac{145.60}{100}=1.456 \\
& k_{L A}=\frac{L_{C}}{L_{N}}=\frac{178.44}{100}=1.784
\end{aligned}
$$

where $L_{N}$ is the initial chord length. The x coordinates of characteristic points along the upper and the lower curves are recomputed as follows:

$$
P_{A X}=P * k_{L A}
$$




$$
\begin{aligned}
& P_{B X}=P * k_{L B} \\
& P_{C X}=P * k_{L C}
\end{aligned}
$$

The coordinates of individual points along the sub-profile curves are shown in Table 2. Figure 4 shows the new sub-profiles that were obtained with the given procedure. In common points of upper and lower sub-profile, the round-off is carried out. The radius of the leading-edge round is equal on all sub-profiles, as well as the radius of the round on the trailing edge. The rounding-off process resulted in a slight reduction of the chord length. The round-off radius must be reasonably small to obtain a consistent blade, preventing unwanted deformations or edge chipping.

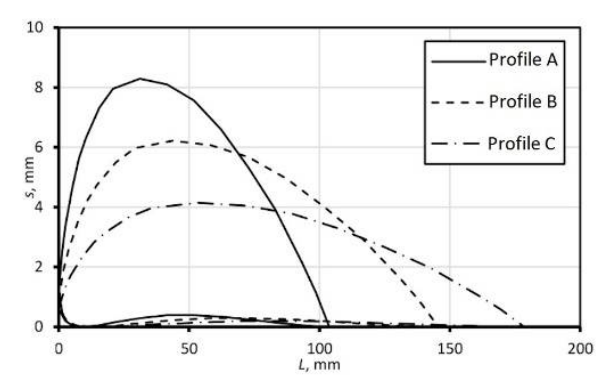

(a)

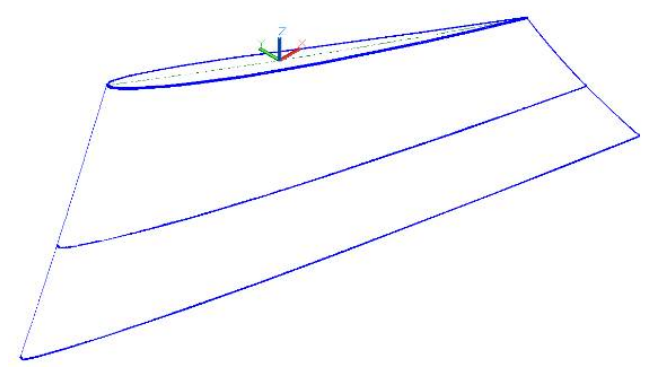

(b)

Figure 4. Blade sub-profiles obtained during the adjustment procedure (a) and their transformation through the sub-profiles spaced according to the calculations (b).

Another crucial aspect which must be considered during the blade design process is the design of an optimal blade hub mounting. To obtain an undisturbed flow, the presence of hub blade slots, sprues, or a protruding mounting is highly undesirable. In practice, we are looking for a compromise between the minimisation of flow disturbances and blade mounting machining costs.

An additional difficulty arises with the design of a consistent and clearly defined blade hub connection along the shaft. In the presented turbine, it was decided to connect the blades to the rotor hub using conical pins. Introducing additional holes in the rotor hub allowed for the possibility to adjust the blade incident angle, after the disassembly of the flow system.

The experimental studies were conducted for the obtained aerofoils and turbine geometries. The results for four- and five-bladed rotors with equal internal and external diameters were very promising. The experimental studies were conducted for both geometries with similar flow conditions.

\section{Experiment}

\subsection{Test Rig}

The turbine elements were manufactured in technical plants in Poland, whose many years of practical experience and mastery of manufacturing allowed for the production of turbomachines up to 12 meters in diameter. PA6 aluminium alloy was selected for the production of a prototype turbine. The turbine blades were made using multi-axis milling but were not subjected to surface hardening or forging since they did not need to operate in contaminated water. The plastic elements, such as the guide tube of the axial rotor, are made of polyamide. Zinc-coated screws with variable hardness, depending on the location of the screw, were used for the assembly of individual components. O-ring seals used in the turbine were made of NBR rubber since it was assumed that they would be operating at temperatures of up to $35^{\circ} \mathrm{C}$ in non-contaminated water, containing no acids or bases. The bearing system was made of ceramic bearings with little frictional resistance. The sealing sleeves are individually made of BA type aluminium bronze. 
Once manufactured, the water turbine was studied on a dedicated test rig at the Laboratory of Hydraulic Machines at the Silesian University of Technology. Figure 5 shows a schematic sketch of the test rig. The water, of temperature $t$, measured with a Pt100 thermocouple, is supplied by a one-stage pump (LFP 300 WM 270) with a varying rotational velocity, directly to a $1 \mathrm{~m}^{3}$ container, where its kinetic energy is reduced. The water flow rate is measured with an electromagnetic flowmeter. From the container, the water is directed to an open trough, before being directed into the rotor of the water turbine. The water that leaves the turbine is directed to a $90 \mathrm{~m}^{3}$ underground container. Table 3 shows the measurements from the flow meter. The minimum velocity of the supplied water, $0.5 \mathrm{~ms}^{-1}$, was achieved by reducing the diameter of the pipe downstream of the pump. The pipe sections, which were of reasonable length upstream and downstream of the flow meter, were kept to give reliable results. The water height at the inlet of the turbine's stator was measured with a water gauge and pressure sensor.

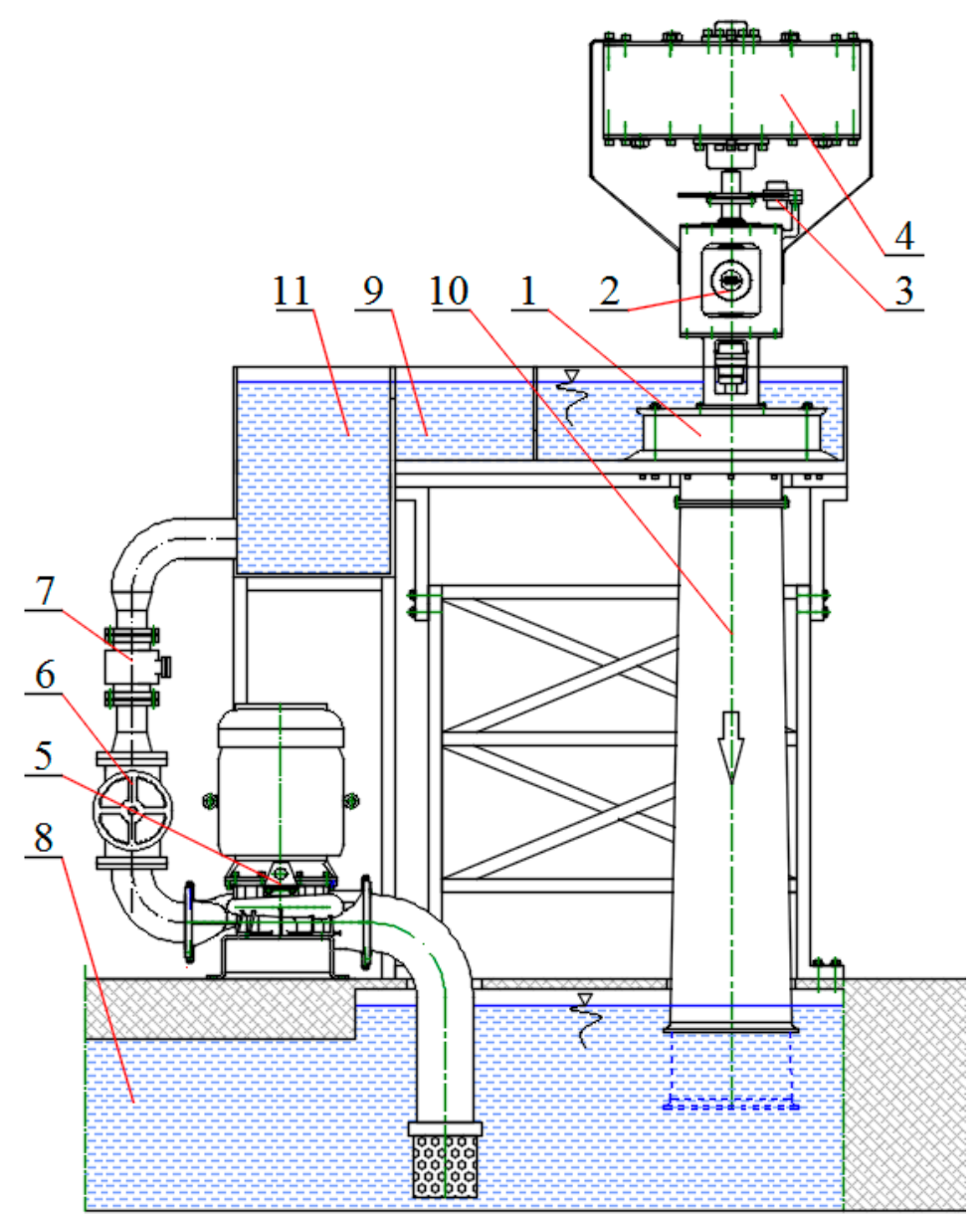

Figure 5. Test rig. 1-Kaplan water turbine, 2-strain gauge, 3-auxiliary brake, 4-hydraulic brake, 5-supplying pump, 6-regulation valve, 7-electromagnetic flow-meter, 8-underground container $\left(80 \mathrm{~m}^{3}\right)$, 9-inflow trough $(3.9 \mathrm{~m}), 10$-turbine drain pump $(1.4 \div 2.4 \mathrm{~m}), 11$-expansion tank $\left(1.3 \mathrm{~m}^{3}\right)$.

The change in water height was achieved by changing the volume of the liquid in the underground container. As a result, the total water height, $h$, is the sum of the water height at the inlet to the turbine, $h_{z}$, and the distance between the turbine and the underground container, $h_{p}$.

$$
h=h_{z}+h_{p}
$$

The hydraulic power, $P_{h}$, i.e., the energy of water flowing through the turbine is defined as follows:

$$
P_{h}=g \cdot \rho \cdot \dot{Q} \cdot h
$$


where $g$ is the gravitational acceleration, $\rho=f(t)$ is the density of water in the function of its temperature, and $\dot{Q}$ is the water volume flow rate.

The shaft power, $P_{w}$ defined as follows:

$$
P_{w}=M \cdot w
$$

where $M$ is the torque, and $\omega$ is the rotational velocity. The torque and rotational velocity were measured with a strain gauge.

If the measuring range and class of the applied device are known, type 5 uncertainty can be applied to define the measurement accuracy. During the measurements, there were no significant changes in the measured values; therefore, it was assumed that the steadystate conditions were reached. The measurement of all quantities was simultaneous. Due to the interaction of the strain gauges with analogue-to-digital converters, the uncertainty of indications $\left(C \_2=0\right)$ that resulted from the class of transducers has been omitted-this is because they are measured with an accuracy that is an order of magnitude higher.

\subsection{Measurement Uncertainty}

Experimental research in the Laboratory of Fluid Flow Machines at the Department of Power Engineering and Turbomachinery has been ongoing for 60 years. During that time, the laboratory has always been equipped to carry out research for industry and academia. Measuring instruments that are used in the laboratory are systematically calibrated. Due to its size, the electromagnetic flowmeter used in the measurement (DM200) was calibrated outside of the laboratory. Calibration of the flow meter was performed using the volumetric method with a gravitational inflow of water. Due to the force required, the strain gauge was calibrated in the laboratory with a standard load over a length of $1 \mathrm{~m}$. For the measurement of the rotational speed, the calibration was performed using a strobe lamp. The measurements that are recorded by the instruments are therefore validated by the manufacturer's calibrations. The uncertainty of relevant quantities for turbine efficiency study is shown in Table 3.

The uncertainty determined further is related to the uncertainty of measuring instruments [19]. For the measuring scope used, the type B uncertainty is calculated for a rectangular distribution, as shown below:

$$
u_{x}=\frac{\Delta x}{\sqrt{3}}
$$

Table 3. Relevant quantities measurement for turbine efficiency calculation.

\begin{tabular}{cccccc}
\hline $\begin{array}{c}\text { Measured } \\
\text { Quantity }\end{array}$ & Designation & Unit & $\begin{array}{c}\text { Minimal Scope } \\
\boldsymbol{\Delta x}\end{array}$ & Measuring Range & $\begin{array}{c}\text { Standard } \\
\text { Uncertainty } \boldsymbol{u}_{\boldsymbol{x}}\end{array}$ \\
\hline Height & $h$ & $\mathrm{~m}$ & 0.001 & 1 & 0.005774 \\
Volume flow rate & $\dot{Q}$ & $\frac{\mathrm{m}^{3}}{\mathrm{~min}}$ & 0.036 & $0-18$ & 0.020785 \\
Torque & $\mathrm{Nm}$ & $\mathrm{RPM}$ & 2 & 20 & 0.011547 \\
Rotational speed & $n$ & ${ }^{\circ} \mathrm{C}$ & 0.2 & 6000 & 0.154701 \\
Water temperature & $t$ & & $-50 \div 270$ & 0.11547 \\
\hline
\end{tabular}

For the demonstration case, the uncertainty of the water temperature measurement is neglected, and its constant density is assumed to equal to $\rho=998.62 \mathrm{~kg}^{-1} \mathrm{~m}^{3}$ for $t=18{ }^{\circ} \mathrm{C}$. The following equation includes the measured quantities needed to compute the combined standard uncertainty. The results of the following reasoning are shown in Table 4:

$$
\eta_{T}=\frac{M \cdot \pi \cdot h}{30 \cdot g \cdot \rho \cdot \dot{Q} \cdot h} \cdot 100 \%
$$


Table 4. Example of values measured simultaneously for one measuring point and the calculated partial derivative.

\begin{tabular}{ccccc}
\hline $\begin{array}{c}\text { Measured } \\
\text { Quantity }\end{array}$ & Designation & Unit & Measured Value & $\begin{array}{c}\text { Partial } \\
\text { Derivative }\end{array}$ \\
\hline Height & $h$ & $\mathrm{~m}$ & 2.13 & 3.365 \\
Volume flow & $\dot{Q}$ & $\frac{\mathrm{m}^{3}}{\mathrm{~s}}$ & 0.005355 & 1338.9 \\
rate & $\mathrm{Nm}$ & 0.10622 & 67.497 \\
Torque & $n$ & $\mathrm{RPM}$ & 721 & 0.009944 \\
\hline
\end{tabular}

Partial derivatives of efficiency with respect to the subsequently measured quantities take the following form:

$$
\begin{aligned}
\frac{d \eta_{T}}{d M} & =\frac{\pi \cdot n}{30 \cdot g \cdot \rho \cdot \dot{Q} \cdot h} \cdot 100 \% \\
\frac{d \eta_{T}}{d n} & =\frac{\pi \cdot M}{30 \cdot g \cdot \rho \cdot \dot{Q} \cdot h} \cdot 100 \% \\
\frac{d \eta_{T}}{d \dot{Q}} & =\frac{-M \cdot \pi \cdot h}{30 \cdot g \cdot \rho \cdot \dot{Q}^{2} \cdot h} \cdot 100 \% \\
\frac{d \eta_{T}}{d h} & =\frac{-M \cdot \pi \cdot n}{30 \cdot g \cdot \rho \cdot \dot{Q} \cdot h^{2}} \cdot 100 \%
\end{aligned}
$$

Combined standard uncertainty is computed employing a general equation for $x_{i}=M, n, Q, h$ as follows:

$$
u_{C}\left(\eta_{T}\right)=\sqrt{\sum_{x_{i}}\left[\frac{\partial \eta_{T}}{\partial\left(x_{i}\right)}\left(x_{i}\right)\right]^{2} \cdot u_{x}^{2}\left(x_{i}\right)}
$$

By substituting the values, it is possible to obtain the efficiency of a turbine and the measurement uncertainty $\eta_{T}=83.97(1.57) \%$.

\subsection{Experimental Study}

The studies were performed for five-bladed rotors, as well as for an alternative solution with four blades (see Figure 6). The efficiencies of the turbines, based on the experimental studies, are presented in Figure 6. In both studies, the rotors worked in the same channel. The maximum efficiency and the working range within the efficiency range between $\eta_{\max }$ and $\eta_{\max }-10 \%$ are similar. The system with four blades is more greatly affected by the stator blade incidence angle than the system with five blades. The five-blade system shows less sensitivity to the initial flow swirl. The sudden drop in the efficiency for the stator blade incidence angle, of around $60^{\circ}$, is induced by losses that are caused by the disturbance of the flow and the flow parameter drop at the inlet to the turbine. In the presented system, the maximum reasonable incidence angle is $55^{\circ}$. The high value of power that was obtained, $1.2 \mathrm{~kW}$, and efficiency for a pico turbine, are the results of precise machining of the system's elements and accurate blade machining, which resulted in smooth PA6 aluminium blades. In the proposed turbine, the water flowing through the bearing system provides cooling and lubrication. The construction of the turbine eliminates the necessity for seals. The power was measured by a tensometric manometer on the turbine's hub, using the oil brake $[20,21]$. 

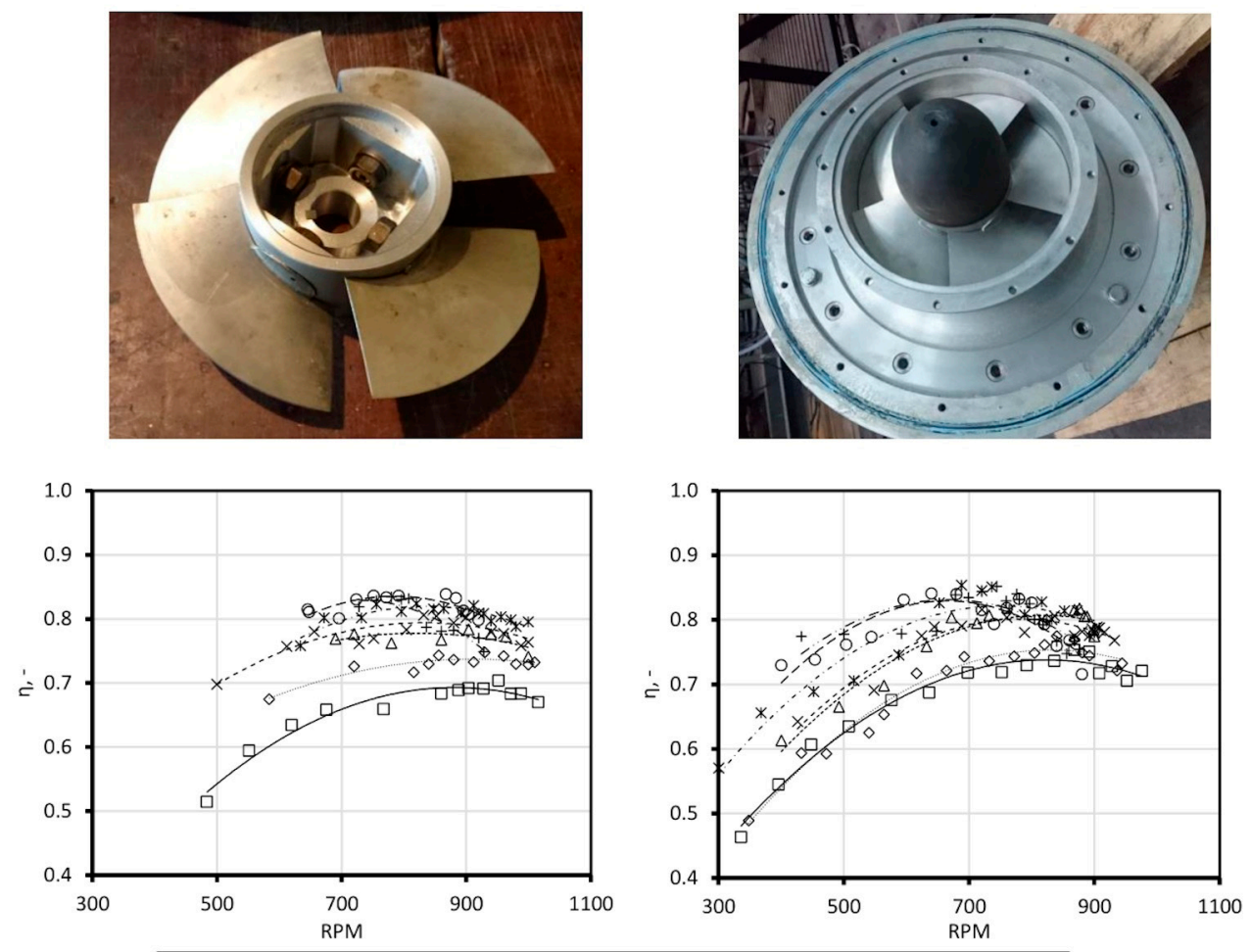

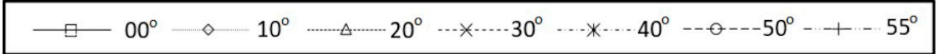

Figure 6. Kaplan turbines: four- and five-bladed rotors and turbines' efficiency for various stator blades incidence angle for four- and five-bladed rotors.

\section{Numerical Studies}

\subsection{Blade Numerical Studies}

To define the aerofoil characteristics, the numerical analysis of the sub-profiles obtained by the described method was performed. The numerical studies were carried out using commercial software, ANSYS Fluent (ver.2020R1, ANSYS Inc., Canonsburg, PA, USA). A mesh was created for each sub-profile. The domain size was chosen based on values from the literature, although it must be acknowledged that the domain size used in the literature was chosen for an airflow-based study [22-24]. A boundary layer was introduced to ensure that the $y^{+}$function value was approximately 1 . The growth ratio of the following layers was equal to 1.05. The turbulence effect is modelled using the $k-\omega$ shear-stress transport (SST) model proposed by Mentner $[25,26]$. Figure 7 shows the domain size and the mesh boundary layer. The number of elements for sub-profiles A, B, and $C$ is as follows: $460182,466372,472470$.
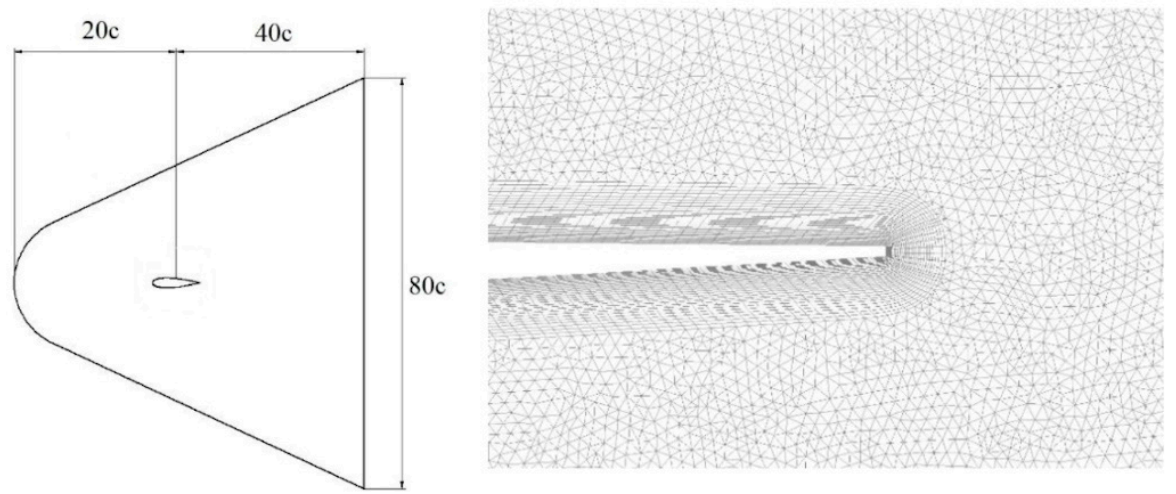

Figure 7. Domain size (left) and mesh boundary layer (right). 
Several simulations were conducted to calculate the lift and drag coefficients as a function of the incidence angle. The water was assumed to be incompressible and the energy equation was neglected. These assumptions are justified by the low flow velocities and negligible changes in the fluid pressure. The calculations were carried out for a range of incidence angles that are characteristic of a water turbine flow system-between $0^{\circ}$ and $25^{\circ}$. The inflow velocity for the studies was assumed to be $3.5 \mathrm{~ms}^{-1}$, which is the maximal meridional velocity in the turbine, based on the empirical calculations. Figure 8 shows the drag and lift coefficient curves for each aerofoil. There is a sudden drop in the lift coefficient when the angle of attack equals $10^{\circ}$, which is induced by the boundary layer separation. This phenomenon is called a 'stall'.

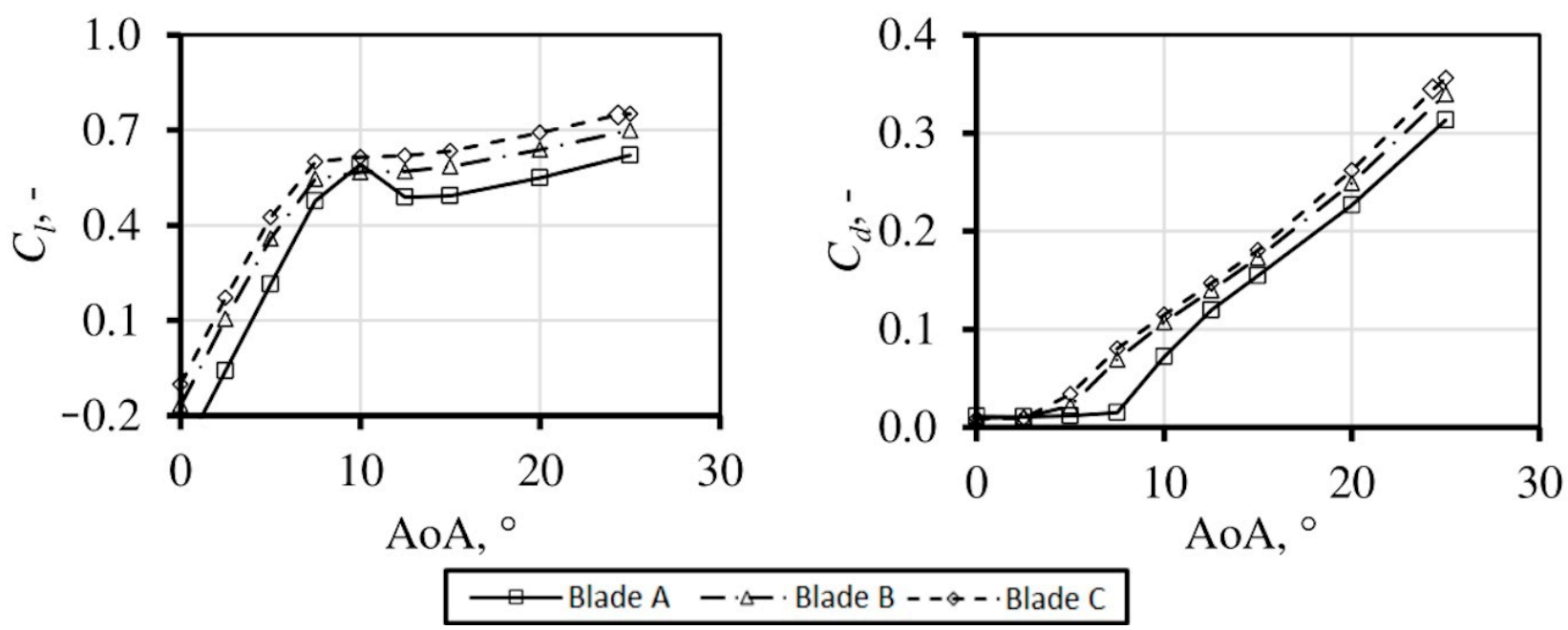

Figure 8. Lift and drag coefficients in the function of incidence angle for blade A, B, and C cross sections (see Figure 4).

\subsection{Flow System Numerical Studies}

The flow system was modelled and assessed. In the presented case, the calculations were carried out for the whole system, which accounted for the inflow of the water, the stator stage with adjustable blades, and the outflow pipe. The outflow pipe was designed as a cylinder, in line with literature recommendations. In the literature, multi-stage outflow diffusers are usually recommended. In the described case, the drop mostly occurs in the outflow channel; therefore, to avoid the cavitation, the inflow velocity should not exceed $2 \mathrm{~ms}^{-1}$.

The numerical studies were performed in commercial software ANSYS CFX (ver.2020R1, ANSYS Inc., Canonsburg, PA, USA). The model consists of connected parts of the flow system to ensure reasonable mesh density and the number of elements. The computational domain and mesh are depicted in Figure 9; the mesh consisted of $\sim 8$ million elements. The steady-state condition was assumed; thus, no changes of flow character with time were considered. The boundary conditions were described using the mass flow inlet and pressure outlet, and the rotational velocity was given. The turbulence effect is modelled using the $k-\omega$ shear-stress-transport (SST) model proposed by Mentner. The boundary layer was introduced to ensure that the $y+$ function value equalled approximately 1 , and the growth ratio of the following layers equalled 1.05. The flow is assumed to be isothermic, with a constant temperature of $25^{\circ} \mathrm{C}$. 


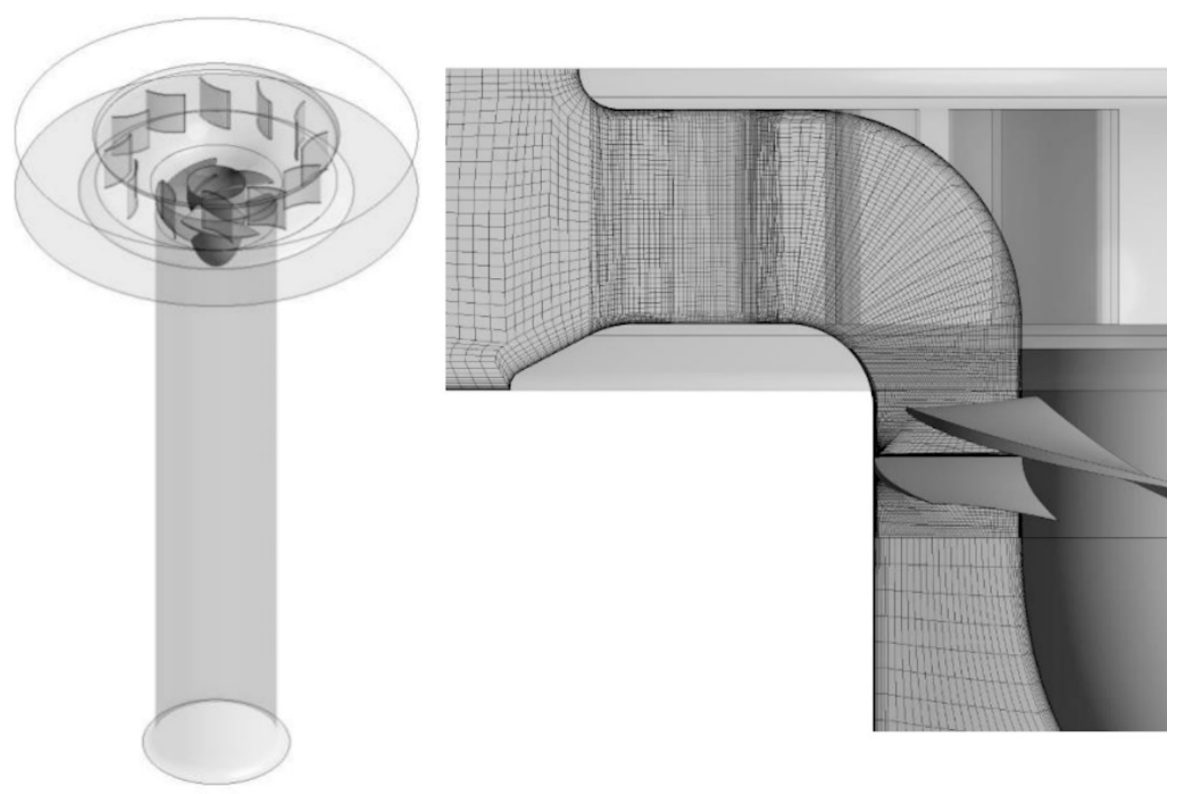

Figure 9. The schematic view of the domain and the mesh.

Two series of computations were conducted for different inlet blade incidence angles, varying the volume flow in the range between $2.5 \mathrm{~m}^{3} \mathrm{~min}^{-1}$ and $5.5 \mathrm{~m}^{3} \mathrm{~min}^{-1}$ and varying rotational velocity within the range of 300 to $1000 \mathrm{RPM}$. The computed maximum efficiency of the turbine equalled $72.5 \%$ and $84 \%$ for the stator blade incidence angles of $0^{\circ}$ and $45^{\circ}$, respectively. The computational results are in good agreement with experimental studies, which, for equivalent conditions, indicated efficiencies of $70 \%$ and $84 \%$, for stator blade incidence angles of $0^{\circ}$ and $45^{\circ}$, respectively. The velocity and pressure distribution in the flow system for the case study with maximum efficiency are shown in Figure 10, which shows no local pressure changes or boundary layer separation. Figure 11 presents the pressure distribution on the rotor's blades. The pressure distribution, visible in Figure 11, confirms the assumed lack of local pressure changes on the surface of the blades. This confirms the correct design of the variability of the geometry of the flow profiles, which allows for a higher maximum value, for a given ratio of the speed of the flow system to the rotor efficiency. This was confirmed also by empirical research that was carried out in the laboratory.
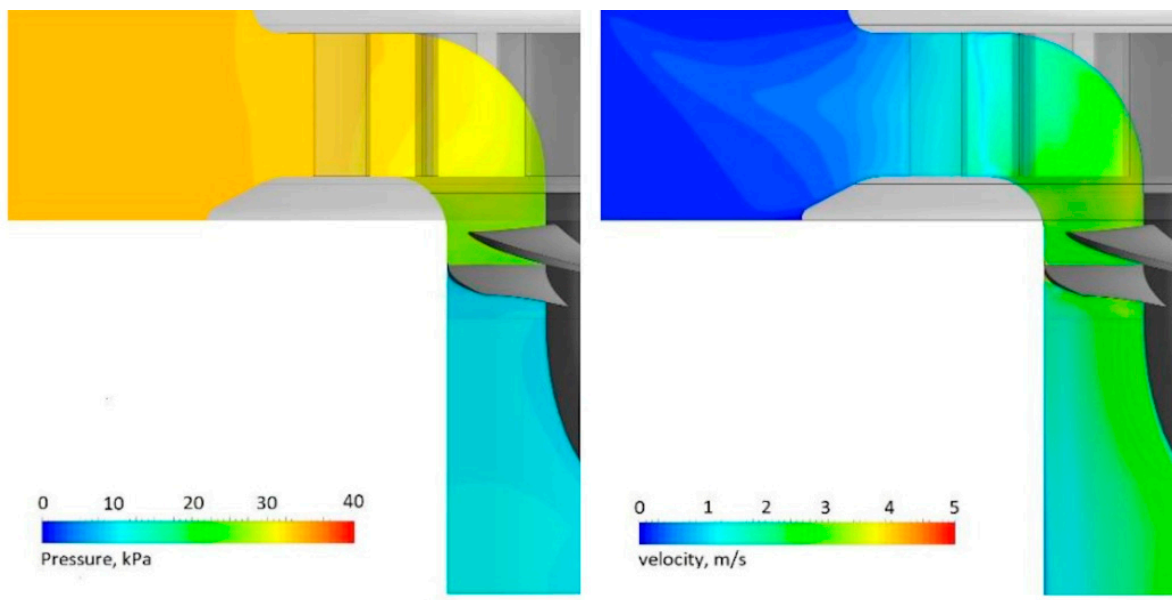

Figure 10. Water pressure and velocity in the turbine based on the numerical studies. 


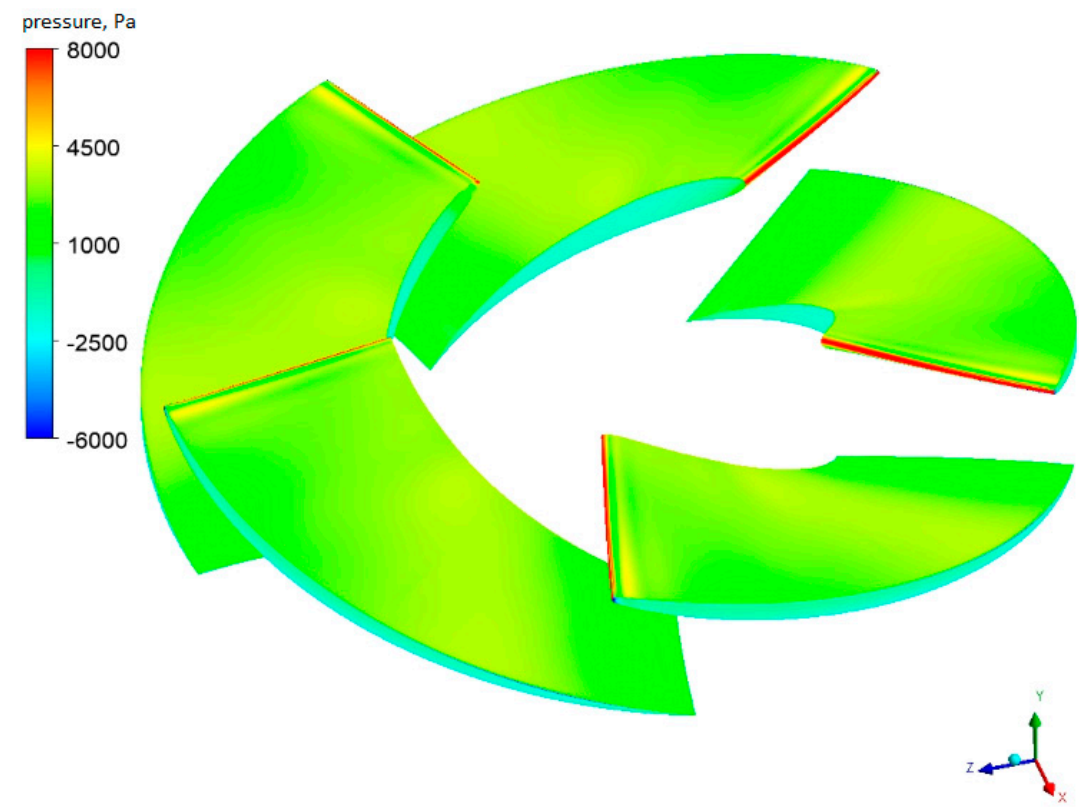

Figure 11. The pressure distribution on the rotor's blade surfaces, based on the numerical studies.

\section{Conclusions}

This paper presents the experimental and numerical study of a small Kaplan turbine. Within the paper, an approach is used to tailor blade profiles, which are designed for airflow applications, for use with a specific, small, power water turbine. The simplified method of blade adjustment presented in this article allows for the design of turbine blade geometry, based on the airflow reference blade from available databases. The proposed approach was applied to the design of two turbines, differing in the number of blades. These were manufactured and studied both experimentally and numerically.

The results of the experimental study for the two turbines are presented. The influence of rotational velocity and stator blade incidence angle was studied. The efficiency of designed turbines reached up to $84 \%$. The results obtained during the experimental studies confirmed the accuracy of the proposed method for turbine blades' design.

In the numerical studies, the lift and drag coefficients were calculated as a function of the angle of attack, which was applied to the newly created sub-profiles of the turbine blade. For the A sub-profiles, stalling occurred at an angle of attack equal to $\sim 10^{\circ}$. For sub-profiles $B$ and $C$, stalling did not occur; however, due to boundary layer separation, the increase of lift beyond an angle of attack equal to $\sim 10^{\circ}$ was shown to result in significant drag.

Numerical studies were carried out for the whole flow system. The studies were performed with varying rotational velocity and volume flow rate. The numerical tool slightly underestimated the efficiency of the turbines, when compared to the experimental study. This can be caused by the use of assumptions within the numerical tool, e.g., isothermal flow, or may have been induced by the imperfect mesh, which may have resulted in gap leakage - which, for small turbines, has a significant influence on the efficiency. This issue needs to be studied further since it opens possibilities for the development of numerical models for water machinery computations.

The value of the small turbine does not reflect the time devoted to this study; however, it confirms the utility of the described method and its implementation in the design process. The presented turbines are promising, low-cost solutions for harvesting energy from relatively small water flows with low energy potential. Such a turbine has potential in numerous, so far undeveloped, small water flows in forested areas. Moreover, the presented results, especially due to the high efficiency of mechanical power generation, confirm the potential of small turbines in energy generation, especially when the added flexibility to the power grid is considered. 
Author Contributions: Conceptualization, G.P. and P.W.; methodology, G.P.; software, P.W.; validation, G.P. and A.Z.; formal analysis, G.P.; investigation, P.W.; resources, G.P.; data curation, G.P.; writing—original draft preparation, P.W.; writing_review and editing, A.Z.; visualization, P.W. All authors have read and agreed to the published version of the manuscript.

Funding: This research received no external funding.

Institutional Review Board Statement: Not applicable.

Informed Consent Statement: Not applicable.

Data Availability Statement: Not applicable.

Conflicts of Interest: The authors declare no conflict of interest.

\section{Nomenclature}

Symbols

\begin{tabular}{|c|c|}
\hline AoA & angle of attack, ${ }^{\circ}$ \\
\hline$c$ & chord length, m \\
\hline C & coefficient, - \\
\hline$D$ & drag, $\mathrm{N}$ \\
\hline$g$ & gravity acceleration, $\frac{m}{s^{2}}$ \\
\hline$h$ & water height, $m$ \\
\hline$k$ & adjustment coefficient, - \\
\hline$L$ & length, $\mathrm{m}$ \\
\hline$L$ & lift, $\mathrm{N}$ \\
\hline$M$ & torque, $\mathrm{Nm}$ \\
\hline$n$ & rotational speed, RPM \\
\hline$P$ & power, $W$ \\
\hline $\mathrm{P}, \mathrm{R}$ & points along blade suction and pressure side, \\
\hline$\dot{Q}$ & volume flow rate, $\frac{\mathrm{m}^{3}}{\mathrm{~s}}$ \\
\hline $\operatorname{Re}$ & Reynolds number, - \\
\hline$s$ & blade thickness, m \\
\hline$t$ & water temperature, ${ }^{\circ} \mathrm{C}$ \\
\hline$u$ & free stream velocity $\frac{m}{s}$ \\
\hline$u$ & uncertainty, - \\
\hline$\beta$ & blade incident angle \\
\hline$\eta$ & efficiency, - \\
\hline$v$ & kinetic viscosity, $\frac{m^{2}}{s}$ \\
\hline$\rho$ & density, $\frac{\mathrm{kg}}{\mathrm{m}^{3}}$ \\
\hline$\Omega$ & angular velocity, $s^{-1}$ \\
\hline \multicolumn{2}{|l|}{ Subscripts } \\
\hline 1 & inlet \\
\hline 2 & outlet \\
\hline A, B, C & sub-profile \\
\hline $\mathrm{b}$ & B type \\
\hline c & combined \\
\hline $\mathrm{D}$ & drag \\
\hline $\mathrm{h}$ & hydraulic \\
\hline $\mathrm{L}$ & lift \\
\hline $\mathrm{L}$ & length \\
\hline $\max$ & maximum \\
\hline $\mathrm{p}$ & turbine outlet \\
\hline s & thickness \\
\hline$T$ & turbine \\
\hline $\mathrm{w}$ & shaft \\
\hline Z & turbine inlet \\
\hline
\end{tabular}




\section{References}

1. Jedral, W. Res and Energy efficiency in context of challenges for electricity generation and utilization of Energy in Poland. Rynek Energii 2019, 1, 3-8.

2. Sritram, P.; Suntivarakorn, R. Comperative Study of Small Hydropower Turbine Efficiency at Low Head Water. Energy Procedia 2017, 138, 646-650. [CrossRef]

3. Wiliamson, S.J.; Stark, B.H.; Booker, J.D. Performance of a low-head pico-hydro Turgo turbine. Appl. Energy 2013, 102, 1114-1126. [CrossRef]

4. $\quad \mathrm{Du}, \mathrm{J} . ;$ Yang, H.; Shen, Z.; Chen, J. Micro hydro power generation from water supply system in high rise buildings using pump as turbines. Energy 2017, 137, 431-440. [CrossRef]

5. Rentschler, M.; Maraongiu, J.; Neuhauser, M.; Parkinson, E. Overview of SPH-ALE applications for hydralic turbines in ANDRITZ hydro. J. Hydrodyn. 2018, 30, 114-121. [CrossRef]

6. Lahimer, A.A.; Alghoul, M.A.; Sopian, K.; Amin, N.; Asim, N.; Fafhel, M.I. Research and development aspects of pico-hydro power. Renew. Sustain. Energy Rev. 2012, 16, 5861-5878. [CrossRef]

7. Zhao, J.; Wang, L.; Liu, D.; Wang, J.; Zhao, Y.; Liu, T.; Wang, H. Dynamic model of Kaplan turbine regulating system suitable for power system analysis. Math. Probl. Eng. 2015, 2015, 1-12. [CrossRef]

8. ISE Fraunhofer. 2020. Available online: https://www.ise.fraunhofer.de/de/presse-und-medien/presseinformationen/2020 /nettostromerzeugung-im-ersten-halbjahr-2020-rekordanteil-erneuerbarer-energien.html (accessed on 1 January 2021).

9. Ujwala, M.; Chowdary, C.K.; Srinivas Naik, L. Design and Analysis of Low Head, Light weight Kaplan Turbine Blade. Int. Refereed J. Eng. Sci. 2017, 6, 17-25.

10. Bruschi, D.L.; Fernandes, J.C.; Falcao, A.F.; Bergmann, C.P. Analysis of the degradation in the Wells turbine blades of the Picooscillating-water-column wave energy plant. Renew. Sustain. Energy Rev. 2019, 115, 109368. [CrossRef]

11. Soukala, J.; Pochylyb, F.; Varcholac, M.; Parygind, A.G.; Volkovd, A.V.; Khovanovd, G.P.; Naumov, A.V. Selection of Axial Hydraulic Turbines for Low Head Microhydropower Plants. Therm. Eng. 2015, 62, 862-867. [CrossRef]

12. Sosilo, A.K.; Hadi, H.; Soehartanto, T. Design of Hydro Power by Using Turbines Kaplan on The Discharge Channel Paiton 1 and 2. In Proceedings of the E3S Web of Conferences, Yogyakarta, Indonesia, 1 November 2017.

13. Chen, H.; Zhou, D.; Zheng, Y.; Jiang, S.; Yu, A.; Guo, Y. Load rejection Transient Process Simulation of a Kaplan Turbine Model by Co-Adjusting Guide Vanes and Runner Blades. Energies 2018, 11, 3354. [CrossRef]

14. Verchola, M. Hydraulicky Navrh Odstredivych Cerpadiel; STU: Bratislava, Slovakia, 2016.

15. Krzyżanowski, W. Turbiny Wodne Konstrukcja i Zasady Regulacji: Wydawnictwo Naukowo-Techniczne; WNT: Warszawa, Poland, 1971.

16. Abeykoon, C.; Hantsch, T. Design and Analysis of a Kaplan Turbine Runner Wheel. In Proceedings of the 3rd World Congress on Mechanical, Chemical and Material Engineering, Roma, Italy, 8-10 June 2017.

17. Singara, M.; Sammartano, V.; Arico, C.; Collura, A.; Tucciarelli, T. Cross-Flow turbine design for variable operating conditions. Procedia Eng. 2014, 70, 1539-1548. [CrossRef]

18. Muis, A.; Sutkino, P.; Soewono, A.; Hartono, F. Design optimization of axial gydraulic turbine for very low head application. Energy Procedia 2015, 68, 263-270. [CrossRef]

19. BIPM. JCGM 100:2008: Evaluation of Measurement Data-Guide to the Expression of Uncertainty in Measurement. 1995. Available online: https://ncc.nesdis.noaa.gov/documents/documentation/JCGM_100_2008_E.pdf (accessed on 30 April 2021).

20. Dehkarqani, A.S.; Engstrom, F.; Aidanpaa, J.O.; Cervantes, M.J. Experimental Investigation of a 10 MW Prototype Kaplan Turbine during Start-Up Operation. Energies 2019, 12, 4582. [CrossRef]

21. Chirag, T.; Agnalt, E.; Dahlhaug, O.G. Experimental investigation of a Francis turbine during exiqent ramping and transition into total load rejection. J. Hydraul. Eng. 2018, 144, 04018027.

22. Piotr, W.; Francesco, B.; Zbigniew, B.; Alessandro, B. Numerical Analysis on the Effectiveness of Gurney Flaps as Power Augmentation Devices for Airfoils Subject to a Continuous Variation of the Angle of Attack by Use of Full and Surrogate Models. Energies 2020, 13, 1877.

23. Janjua, A.B.; Khalil, M.S.; Saeed, M. Blade profile Optimization of Kaplan Turbine Using CFD Analysis. Mehran Univ. Res. J. Eng. Technol. 2013, 32, 559-574.

24. Borowski, D.; Węgiel, M.; Ocłon, P.; Węgiel, T. CFD model and experimental verification of water turbine integrated with electrical generatior. Energy 2019, 185, 875-883. [CrossRef]

25. Ansys ${ }^{\circledR}$. ANSYS CFX-Solver Theory Guide; Ansys: Canonsburg, PA, USA, 2020.

26. Menter, F.R. Two-equation Eddy-Viscosity Turbulence Models for Engineering Applications. AIAA J. 1994, 32, 1598-1605. [CrossRef] 